\title{
Antagonistic Growth Effects of Mercury and Selenium in Caenorhabditis elegans Are Chemical-Species-Dependent and Do Not Depend on Internal $\mathrm{Hg} / \mathrm{Se}$ Ratios
}

\author{
Lauren H. Wyatt, ${ }^{\dagger}$ Sarah E. Diringer, ${ }^{\ddagger}$ Laura A. Rogers, ${ }^{\ddagger}$ Heileen Hsu-Kim, ${ }^{\ddagger}$ William K. Pan, ${ }^{\dagger} \S$ \\ and Joel N. Meyer* ${ }^{\dagger}$ \\ ${ }^{\dagger}$ Nicholas School of the Environment, ${ }^{\S}$ Global Health Institute, ${ }^{\ddagger}$ Department of Civil and Environmental Engineering, Duke \\ University, Durham, North Carolina 27708, United States
}

\section{Supporting Information}

ABSTRACT: The relationship between mercury $(\mathrm{Hg})$ and selenium (Se) toxicity is complex, with coexposure reported to reduce, increase, and have no effect on toxicity. Different interactions may be related to chemical compound, but this has not been systematically examined. Our goal was to assess the interactive effects between the two elements on growth in the nematode Caenorhabditis elegans, focusing on inorganic and organic $\mathrm{Hg}\left(\mathrm{HgCl}_{2}\right.$ and $\left.\mathrm{MeHgCl}\right)$ and Se (selenomethionine, sodium selenite, and sodium selenate) compounds. We utilized aqueous $\mathrm{Hg} / \mathrm{Se}$ dosing molar ratios that were either above, below, or equal to 1 and measured the internal nematode total $\mathrm{Hg}$ and $\mathrm{Se}$ concentrations for the highest concentrations of each Se compound. Observed interactions were complicated, differed between Se and $\mathrm{Hg}$ compounds, and included greater-than-additive, additive, and less-than-additive growth impacts. Biologically significant interactions were only observed when the dosing Se solution concentration was 100-25000 times greater than the dosing $\mathrm{Hg}$ concentration. Mitigation of growth impacts was not predictable on the basis of internal $\mathrm{Hg} / \mathrm{Se}$ molar ratio; improved growth was observed at some internal $\mathrm{Hg} / \mathrm{Se}$ molar ratios both above and below 1 . These findings suggest that future assessments of the $\mathrm{Hg}$ and Se relationship should incorporate chemical compound into the evaluation.

\section{INTRODUCTION}

Mercury $(\mathrm{Hg})$ is an environmental contaminant of great concern owing to its persistence in the environment; human and wildlife exposures are common, with recognized toxic impacts, making it important to understand factors that can mediate $\mathrm{Hg}$ toxicity. $\mathrm{Hg}$ exists naturally in the environment but also has considerable anthropogenic mobilization, with industrial inputs expected to increase in the future. ${ }^{1}$ In the environment, $\mathrm{Hg}$ exists in three main chemical forms: elemental $\mathrm{Hg}(0)$, inorganic divalent $\mathrm{Hg}(\mathrm{II})$, and organic forms such as monomethylmercury $(\mathrm{MeHg}){ }^{2}$ The majority of human exposures are to inorganic and organic $\mathrm{Hg}$ through occupational and dietary routes, respectively. Chemical speciation is important to toxicity; for example, harmful impacts to the nervous and reproductive systems are associated with $\mathrm{MeHg}$ exposure, and negative renal system impacts are associated with inorganic $\mathrm{Hg}$ exposure. ${ }^{3-6} \mathrm{Hg}$ toxicity can also be altered by a variety of other factors, including selenium coexposure.

Selenium ( $\mathrm{Se}$ ), like $\mathrm{Hg}$, is a naturally occurring element in the environment, but unlike $\mathrm{Hg}$, $\mathrm{Se}$ is a necessary micronutrient. It is necessary for the proper function of selenoenzymes, which have important roles including anti- oxidant functions. Due to its biological importance, organic Se (e.g., selenomethionine) and inorganic Se (e.g., selenate, selenite) have commonly been used in human and animal supplements. However, although Se is required at low levels, it has a very narrow therapeutic index and is toxic at higher concentrations. The interaction between $\mathrm{Hg}$ and Se is complex and has commonly been described as antagonistic, with Se coexposures having the ability to mitigate $\mathrm{Hg}$ toxicity., Conversely, synergistic effects have also been observed. ${ }^{9-11}$ The difference between antagonistic and synergistic impacts may result from the chemical species and dosing concentrations used and may depend on the organism and biological outcome examined. However, the mechanisms that underlie either interaction are not well-understood.

Proposed mechanisms for antagonism include: (1) reductions in bioavailable $\mathrm{Hg}$ due to $\mathrm{Hg}-\mathrm{Se}$ complex formation (i.e., reduced uptake); (2) decreased distribution to target tissues or increased excretion of $\mathrm{Hg}$ due to $\mathrm{Hg}-\mathrm{Se}$ complex formation;

Received: December 9, 2015

Revised: February 18, 2016

Accepted: February 19, 2016

Published: March 3, 2016 
and (3) improved antioxidant function, as some antioxidants are Se-dependent enzymes (ex. glutathione peroxidase, GPX; thioredoxin reductase, TrxR), and supplemental Se could reduce the $\mathrm{Hg}$-induced depletion of selenoenzymes. ${ }^{12,13}$ Related to the first two hypotheses, it has been specifically postulated that the protective effects of Se occur when the molar $\mathrm{Se} / \mathrm{Hg}$ molar ratio is $\geq 1$ because Se may reduce the biological availability of $\mathrm{Hg}$ through physical sequestration due to the high affinity between $\mathrm{Hg}$ and $\mathrm{Se}^{14-17}$ Potential mechanisms for synergism are less clear, but may include altering antioxidant capabilities, thereby promoting a prooxidative environment. ${ }^{8,9,18}$

We sought further knowledge of $\mathrm{Hg}$ and Se interactions by systematically varying multiple chemical species and concentrations in the model organism Caenorhabditis elegans. C. elegans growth was used as the toxic end-point because it represents an integrated measure of multiple developmental processes. Growth impairments from exposure to some species of $\mathrm{Hg}$ or Se individually have also been previously described in C. elegans, making it a logical model to investigate coexposures. ${ }^{19-21}$ Additionally, many antioxidants in C. elegans act similarly to mammalian homologues in terms of reducing oxidative stress (GPX, TrxR, and superoxide dismutase SOD). ${ }^{22-25}$ We note that C. elegans may be a particularly useful model for addressing the antagonism theories described in the preceding paragraph because the likelihood of the third hypothesis is especially low in C. elegans. C. elegans has only one selenoenzyme (TrxR-1) compared to the 25 in humans, ${ }^{26-28}$ deletion of this gene has not been observed to alter Se toxicity in C. elegans, ${ }^{29}$ and low levels of Se stimulate nematode growth $\mathrm{h}^{21,30}$ and are protective against oxidative stress in C. elegans. ${ }^{31-34}$ Our objective was to measure growth impacts from multiple combinations of inorganic and organic forms of $\mathrm{Hg}$ and $\mathrm{Se}$ and, in doing so, examine the importance of (1) Se compound and concentration, (2) $\mathrm{Se} / \mathrm{Hg}$ molar ratio of the exposure medium, and (3) internal $\mathrm{Se} / \mathrm{Hg}$ molar ratio to toxicity recovery.

\section{MATERIALS AND METHODS}

C. elegans Maintenance. N2 (Bristol) nematodes were maintained at $20{ }^{\circ} \mathrm{C}$ on $\mathrm{K}$ agar plates seeded with Escherichia coli (OP50 strain). Synchronized L1 larvae were obtained by treating gravid adults with a $5 \%$ sodium hypochlorite solution and hatching eggs in the absence of food ( $\mathrm{K}$ medium plus $\mathrm{MgSO}_{4}, \mathrm{CaSO}_{4}$, and cholesterol). ${ }^{35}$

Individual Dose-Response Curves for Selecting $\mathrm{Hg}$ and Se Concentrations for the Coexposure Growth Assay. L1 nematodes were distributed into 24 well plates (100-300 nematodes per well in $1 \mathrm{~mL}$ of dosing solution) containing a range of concentrations of $\mathrm{Hg}$ or Se compounds in EPA reconstituted moderately hard water plus UVC-killed E. coli (UVRA strain) to eliminate the potentially confounding effect of bacterial metabolism on exposures, as previously described. ${ }^{36}$ Dose-response curves were obtained for $\mathrm{HgCl}_{2}$ $(0-10 \mu \mathrm{M}), \mathrm{MeHgCl}(0-10 \mu \mathrm{M})$, selenomethionine $(0-1$ $\mathrm{mM}$, SeMeth), sodium selenite $(0-5 \mathrm{mM}, \mathrm{Se}(\mathrm{IV}))$, and sodium selenate $(0-50 \mathrm{mM}, \mathrm{Se}(\mathrm{VI}))$. Nematodes were exposed at 20 ${ }^{\circ} \mathrm{C}$ for $48 \mathrm{~h}$, with additional UVC-killed $E$. coli added after $24 \mathrm{~h}$ ( $5 \%$ of solution volume). Following $48 \mathrm{~h}$, nematode size was measured using a COPAS Biosort (Union Biometrica, Holliston MA), using extinction, the optical density of a nematode, as a growth end-point (72-1479 nematodes measured per exposure). ${ }^{37}$
Compound concentrations for the coexposure growth assay were chosen on the basis of growth reductions. We selected concentrations of 2 and $5 \mu \mathrm{M} \mathrm{MeHgCl}$ and $\mathrm{HgCl}_{2}$ because of their similar impacts on growth (both species caused $\sim 15$ and $\sim 35 \%$ reduction at these doses) and because these exposure levels alter neuromuscular function (locomotion) in $C$. elegans. ${ }^{20}$ We chose Se concentrations that included a high concentration that reduced growth 10-20\% (500 $\mu \mathrm{M}$ SeMeth, $1500 \mu \mathrm{M} \mathrm{Se}(\mathrm{IV})$, and $50 \mathrm{mM} \mathrm{Se}(\mathrm{VI})$ ) along with lower concentrations to assess the impacts of dosing solutions with molar ratios of $\mathrm{Hg} / \mathrm{Se}$ that were either above, below, or equal to 1. Although we did not observe a growth response at the lower Se concentrations $(0.25,2$, and $5 \mu \mathrm{M})$, which could suggest that Se may not be entering the nematodes, these doses were considered appropriate for the coexposure growth assay, as toxicities to other end-points have been observed in this concentration range in other invertebrate studies. We note that although some Se concentrations are high compared to those employed in some other studies, they are sublethal and consistent with previous reports of the same chemicals in studies with C. elegans. ${ }^{19,29,38,39}$

$\mathrm{Hg}$ and Se Coexposure Growth Assay. L1 nematodes were exposed to $\mathrm{HgCl}_{2}, \mathrm{MeHgCl}$, SeMeth, $\mathrm{Se}(\mathrm{IV})$, or $\mathrm{Se}(\mathrm{VI})$ using the same methods that were used to obtain the individual dose-response curves. The following conditions were assayed individually and in $\mathrm{Hg}-\mathrm{Se}$ combinations: control; 2 and $5 \mu \mathrm{M}$ $\mathrm{HgCl}_{2} ; 2$ and $5 \mu \mathrm{M} \mathrm{MeHgCl} ; 0.25,2$, 5, and $500 \mu \mathrm{M}$ SeMeth; $0.25,2,5$, and $1500 \mu \mathrm{M} \mathrm{Se}(\mathrm{IV})$; and 0.25, 2, 5, 1000, 10000, and $50000 \mu \mathrm{M} \mathrm{Se}(\mathrm{VI})$. Following the $48 \mathrm{~h}$ exposure, nematode size was determined (163-409 nematodes per exposure).

Internal $\mathrm{Hg}$ and Se Exposure Determination. L1 nematodes were distributed into $250 \mathrm{~mL}$ tissue culture flasks (49000-85000 nematodes per flask in $30 \mathrm{~mL}$ of dosing solution) and exposed to a range of concentrations of $\mathrm{HgCl}_{2}$, $\mathrm{MeHgCl}, \mathrm{SeMeth}, \mathrm{Se}(\mathrm{IV})$, or $\mathrm{Se}(\mathrm{VI})$. Internal concentrations were only determined for the highest Se concentrations because interactive impacts on growth in combination with $\mathrm{Hg}$ exposure were most clearly present at these exposure levels. Following the $48 \mathrm{~h}$ of exposure, nematodes were washed three times with $\mathrm{K}$ medium and briefly damaged with a Bullet Blender (Next Advance, Averill Park, NY; four repetitions of $15 \mathrm{~s}$ pulses) to break the cuticle. The solution containing damaged nematodes was then centrifuged ( $3 \mathrm{~min}$ at $300 \mathrm{~g}$ ) to remove the cuticle from the solution. The remaining solution was considered to be representative of the internal nematode environment.

Total $\mathrm{Hg}$ concentrations from the internal worm solution were measured using direct thermal decomposition, amalgamation, and atomic absorption spectrometry (Milestone-DMA80). ${ }^{40}$ Analysis of standard reference material (DORM-4 Fish Protein) resulted in $\mathrm{Hg}$ measurements that were $95 \pm 4.2 \%$ of the certified value. The limit of detection (LOD) for $\mathrm{Hg}$ by this method was $0.001 \mathrm{mg} / \mathrm{kg}$. For Se determination, $0.5 \mathrm{~mL}$ of sample was microwave digested in $2.5 \mathrm{~mL}$ of $90 \%$ nitric acid solution (CEM Discover SP-D Microwave Digestion System). Total Se was determined by inductively coupled plasma-mass spectrometry (ICP-MS; Agilent 7700X equipped with Octopole Reaction System). Analysis of a standard reference material (DORM-4 fish protein) resulted in recoveries of 101 $\pm 2.1 \%(n=7)$ of the certified Se value. The LOD for Se by this method was $3.8 \mu \mathrm{g} / \mathrm{L}$. For internal nematode $\mathrm{Hg}$ and $\mathrm{Se}$ determination, the LOD value was used for samples with concentrations below the LOD for each method. $\mathrm{Hg}$ and $\mathrm{Se}$ content were normalized to total protein content to account for 

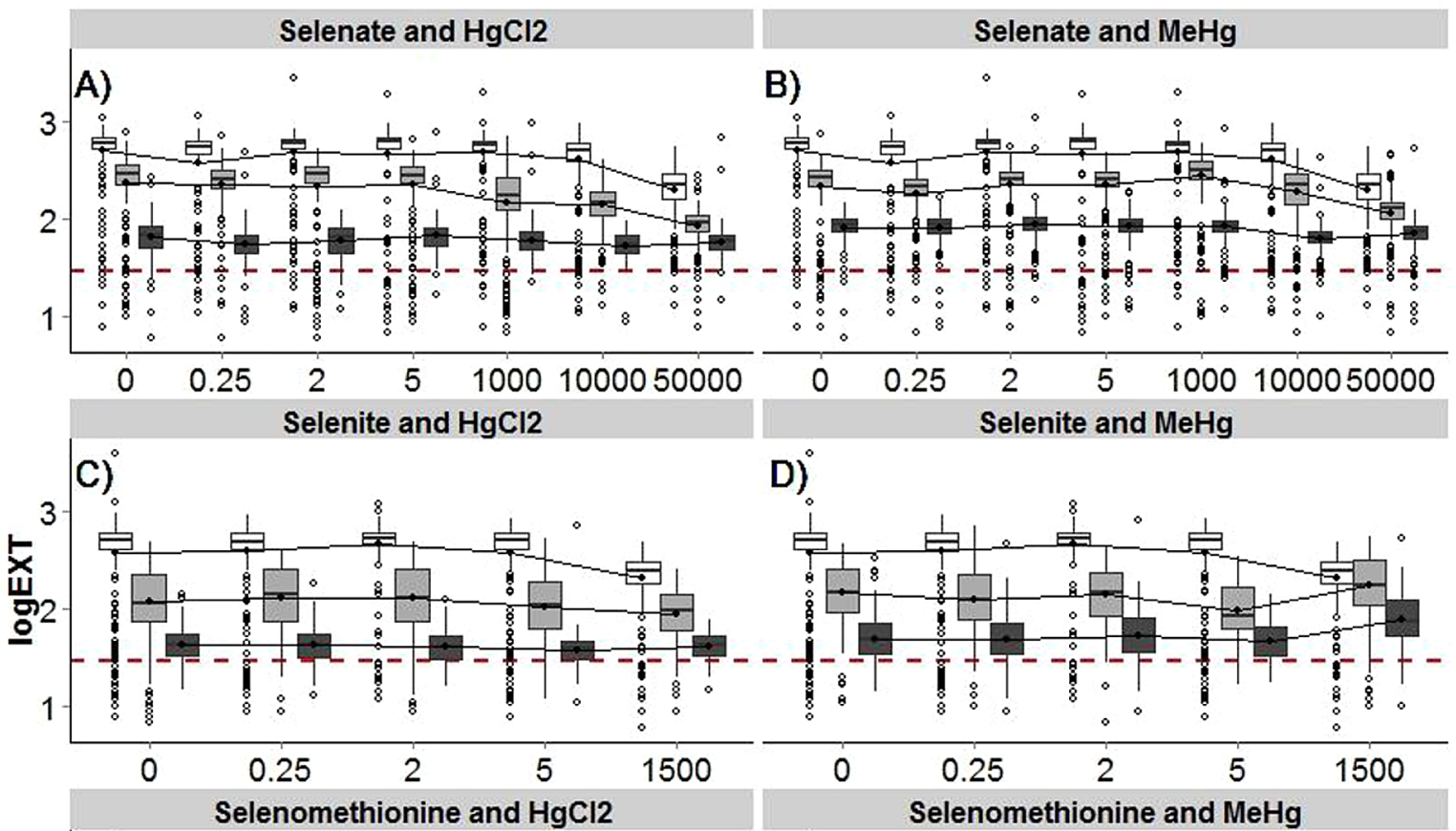

D)

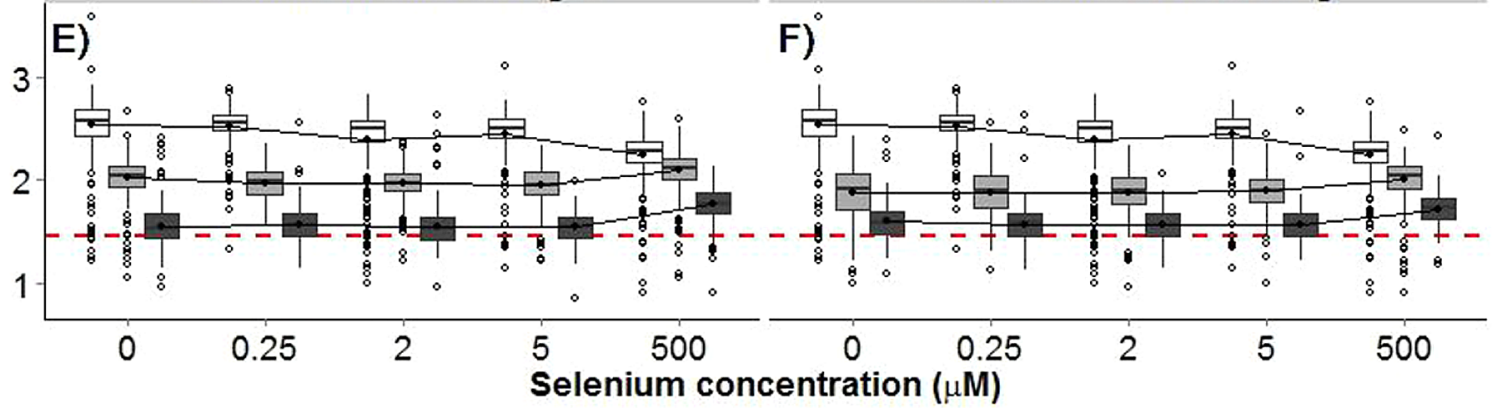

Figure 1. Nematode size $(\log \mathrm{EXT})$ following combination mercury $(\mathrm{HgCl} 2$ and $\mathrm{MeHg}$ ) and selenium (sodium selenate, sodium selenite, and selenomethionine) exposures. Coexposures include: (A) selenate and $\mathrm{HgCl}$, (B) selenate and $\mathrm{MeHg}$, (C) selenite and $\mathrm{HgCl} 2$, (D) selenite and $\mathrm{MeHg}$, (E) selenomethionine and $\mathrm{HgCl} 2$, and (F) selenomethionine and $\mathrm{MeHg}$. Selenium exposure is represented on the $x$-axis against nematode growth $(\log \mathrm{EXT})$, with mercury exposure represented by the grouped lines and box-plots. White box-plots indicate $0 \mu \mathrm{M} \mathrm{Hg}$ exposure, light gray box-plots indicate $2 \mu \mathrm{M} \mathrm{Hg}$ exposure, and dark gray box-plots indicate $5 \mu \mathrm{M} \mathrm{Hg}$ exposure. Data for each group represents three to four biological experiments separated in time with between 163 and 409 individual nematodes. Interaction lines and box-plots are dodged for better visual representation. Lines between box-plots connect the means for each treatment. For each selenium-mercury pairing, mercury altered nematode growth compared to selenium-only exposures $(p<0.05)$. The dashed red line indicates the average nematode size before dosing (L1).

nematode size differences between treatments. Protein content was determined following manufacturer instructions in the bicinchoninic acid (BCA) protein assay kit (Thermo Scientific Pierce BCA Protein Assay Kit). Average protein concentration per sample was approximately $80 \mu \mathrm{g} / \mathrm{mL}$, ranging from 39 to $133 \mu \mathrm{g} / \mathrm{mL}$.

Statistical Analysis. Individual dose-response curves were analyzed using ANOVA, followed by Dunnett's post-hoc test for pairwise comparisons to the control. Interactions between $\mathrm{Hg}$ and Se were assessed by using contrast matrices to measure differences in nematode growth from the coexposure assay. Using these matrices, null hypotheses were defined as additive, with equal weight given to both $\mathrm{Hg}$ and $\mathrm{Se}$ individual exposures. Significant deviations from the null would indicate interactions that were either greater or less than additive, with less than additive responses signifying an antagonistic interaction. Matrices were constructed, for each $\mathrm{Hg}$ and $\mathrm{Se}$ compound pair, in a stepwise manner, and significance was determined using an F-statistic (see Supporting Information). For cases in which the expected nematode size was smaller than the size before dosing, the coexposure treatment was compared to the size before dosing so that the calculated change in growth would not be overinflated. Changes in expected growth were expressed as percentage relative to control nematode growth. A multiplicative model was also assessed, and instances in which multiplicative interactions are significant and differ from additive are described in the text. Additive representations are presented graphically because they are more straightforward to interpret. Additive and multiplicative models were compared using an F-test, Akaike information criterion (AIC), and Bayesian information criterion (BIC) scores. An amelioration of growth inhibition (i.e., toxicity reduction, sometimes described as "rescue" in the pharmacological or genetic literature), is referred to as a reduction or mitigation of toxicity in this manuscript. Internal $\mathrm{Hg}$ and $\mathrm{Se}$ analyses were performed twice, separated in time. The impact of the highest Se exposures on the internal $\mathrm{Hg}$ and Se concentrations and the $\mathrm{Hg} / \mathrm{Se}$ molar ratio was determined using a two-way ANOVA. Statistics were calculated using $\mathrm{R}$ version 3.2.2 (Vienna, Austria), and significance was accepted at a level of $p<0.05$. 


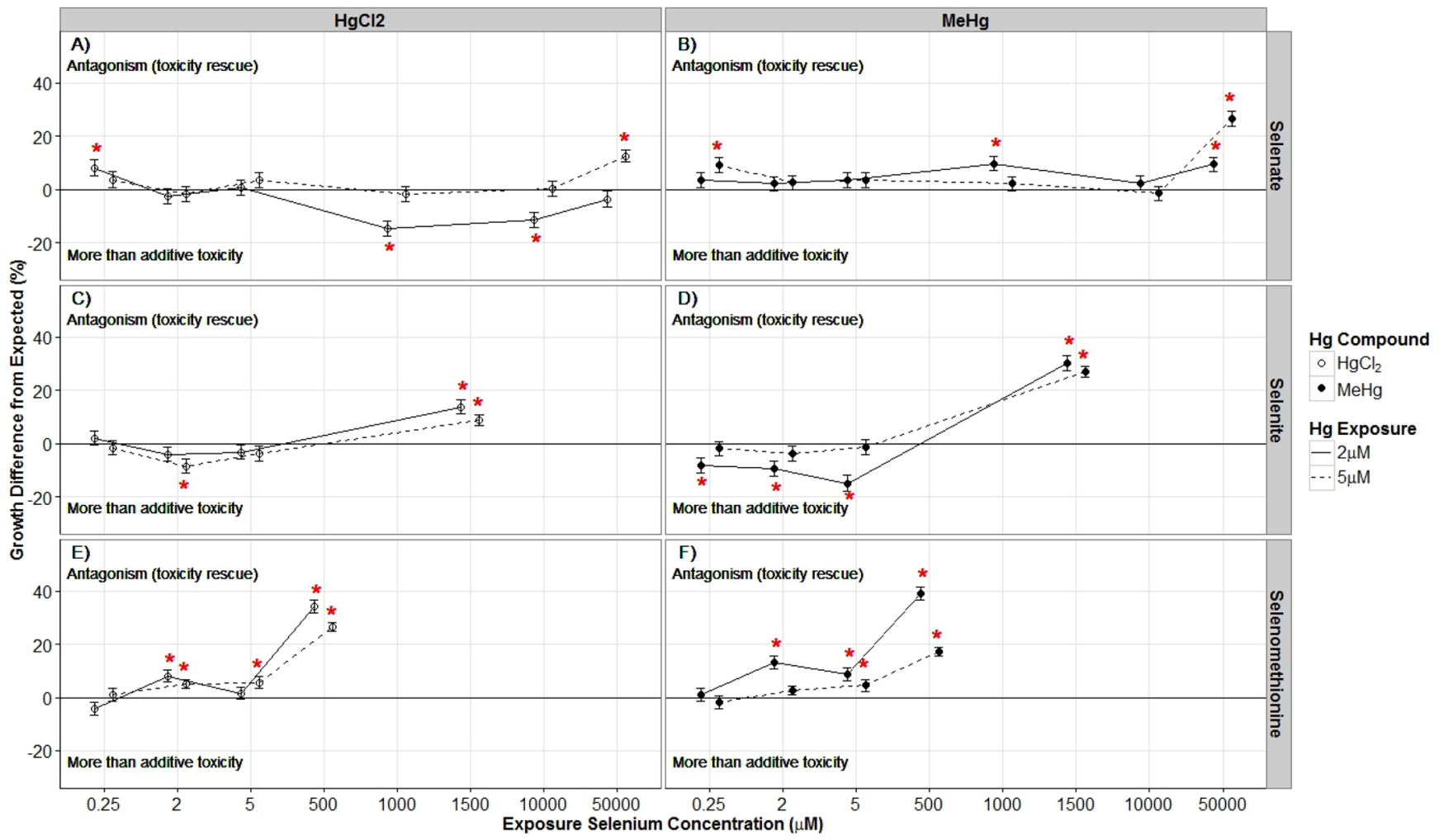

Figure 2. Nematode growth difference (average \% of control $\pm \mathrm{SE}$ ) from expected growth under additive conditions for all selenium and mercury coexposures. Coexposures include: (A) selenate and $\mathrm{HgCl} 2$, (B) selenate and $\mathrm{MeHg}$, (C) selenite and $\mathrm{HgCl}$, (D) selenite and $\mathrm{MeHg}$, (E) selenomethionine and $\mathrm{HgCl}$, and (F) selenomethionine and $\mathrm{MeHg}$. The $x$-axis has categorically increasing selenium exposures $(\mu \mathrm{M})$. $\mathrm{HgCl} 2$ and $\mathrm{MeHg}$ exposures are plotted separately and are indicated by open and closed circles, respectively. Exposure concentration is represented by a solid line for $2 \mu \mathrm{M}$ exposures and a dashed line for $5 \mu \mathrm{M}$ exposures. Positive percentages indicate an antagonistic interaction (more growth than expected) and negative percentages greater than additive interactions (less growth than expected). Asterisks indicate significance compared to the expected additive relationship $(p<0.05)$.

Equilibrium Speciation Calculations. The speciation of $\mathrm{Hg}$ (II) and $\mathrm{MeHg}$ in the $\mathrm{Hg}-\mathrm{Se}(\mathrm{IV})$ and $\mathrm{Hg}-\mathrm{Se}(\mathrm{VI})$ mixtures was calculated using Visual MINTEQ (v. 3.1). Input parameters included the recipe for the EPA moderately hard water matrix (96 mg of $\mathrm{NaHCO}_{3}, 60 \mathrm{mg}$ of $\mathrm{MgSO}_{4}, 60 \mathrm{mg}$ of $\mathrm{CaSO}_{4}$, and $4 \mathrm{mg}$ of $\mathrm{KCl}$ in $1 \mathrm{~L}$ of $\left.\mathrm{H}_{2} \mathrm{O}\right), \mathrm{pH} 7.5$, and $2 \mu \mathrm{M}$ total $\mathrm{Hg}$ (as $\mathrm{Hg}$ (II) or $\mathrm{MeHg}$ ). The concentration of total Se as $\mathrm{Se}(\mathrm{VI})$ or $\mathrm{Se}(\mathrm{IV})$ was varied using the same range as the coexposure experiments (from $0.1 \mu \mathrm{M}$ to $50000 \mu \mathrm{M}$ ). The calculations utilized the thermodynamic stability constants in the Visual MINTEQ database, including constants for $\mathrm{Hg}^{2+}$ complexes with $\mathrm{OH}^{-}, \mathrm{Cl}^{-}$, and $\mathrm{SeO}_{3}{ }^{2-}$. Constants for $\mathrm{CH}_{3} \mathrm{Hg}^{+}$ complexes with $\mathrm{OH}^{-}, \mathrm{Cl}^{-}, \mathrm{SeO}_{3}{ }^{2-}$, and $\mathrm{SeO}_{4}{ }^{2-}$ were obtained from the reference literature (NIST) and manually entered into the program database (Table SI-2). ${ }^{41}$ The calculations assumed that other components of the exposure matrix (e.g., UV-killed bacteria, C. elegans) did not alter the solution-phase speciation of $\mathrm{Hg}$ and $\mathrm{Se}$.

\section{RESULTS}

Individual Dose-Response Curves for Selecting $\mathrm{Hg}$ and Se Concentrations for the Coexposure Growth Assay. Nematodes were exposed to a range of individual $\mathrm{Hg}$ and $\mathrm{Se}$ compound concentrations to evaluate exposure concentrations that impact growth and could be used in the coexposure assay. Data for the individual dose-response curves represents one to nine biological experiments separated in time. All tested $\mathrm{Hg}$ and $\mathrm{Se}$ compounds exhibited dose-responses with respect to growth with the following observed toxicity order: $\mathrm{MeHg} \approx \mathrm{HgCl}_{2}>$ SeMeth $>\mathrm{Se}(\mathrm{IV})>\mathrm{Se}(\mathrm{VI})$ (Figure SI-1 top panel). For individual compounds, the lowest concentrations at which consistent and significant growth reductions were observed were: $1 \mu \mathrm{M} \mathrm{MeHg}, 2 \mu \mathrm{M} \mathrm{HgCl}_{2}, 200$ $\mu \mathrm{M}$ SeMeth, $700 \mu \mathrm{M} \mathrm{Se}(\mathrm{IV})$, and $50 \mathrm{mM} \mathrm{Se}(\mathrm{VI}$ ) (Figure SI-1 bottom panel).

$\mathrm{Hg}$ and Se Coexposure Growth Assay. Next, to assess the interaction between $\mathrm{Hg}$ and $\mathrm{Se}, \mathrm{F}$-statistics were computed to determine if there were significant interactions and whether these interactions were less than additive (antagonistic) or greater than additive. Nematode size for each treatment is displayed in Figure 1. Data for coexposure experiments represents three to four biological experiments separated in time. Initial matrices for all $\mathrm{Hg}-\mathrm{Se}$ comparisons rejected the null hypotheses that $\mathrm{Hg}$ exposure in general $\left(\mathrm{H}_{\mathrm{Aa}}\right)$ and at each dosing concentration $\left(H_{\mathrm{Ab} 1}\right.$ and $\left.H_{\mathrm{Ab} 2}\right)$ had no impact on nematode growth compared to that in Se-only exposures. Additive interaction directionality (antagonistic or more than additive) for each $\mathrm{Hg}-\mathrm{Se}$ pairing is indicated in Figure 2. Multiplicative interactions were significant and different from the additive model at all instances in which growth differed from additive conditions, with the exception of no significant multiplicative interaction at $0.25 \mu \mathrm{M} \mathrm{Se}$ (VI) in combination with $2 \mu \mathrm{M} \mathrm{HgCl}_{2}$. In most instances, differences between additive and multiplicative models was modest (AIC and BIC score difference $<20$ ). However, for coexposures that resulted in more than $15 \%$ growth differences additive and multi- 

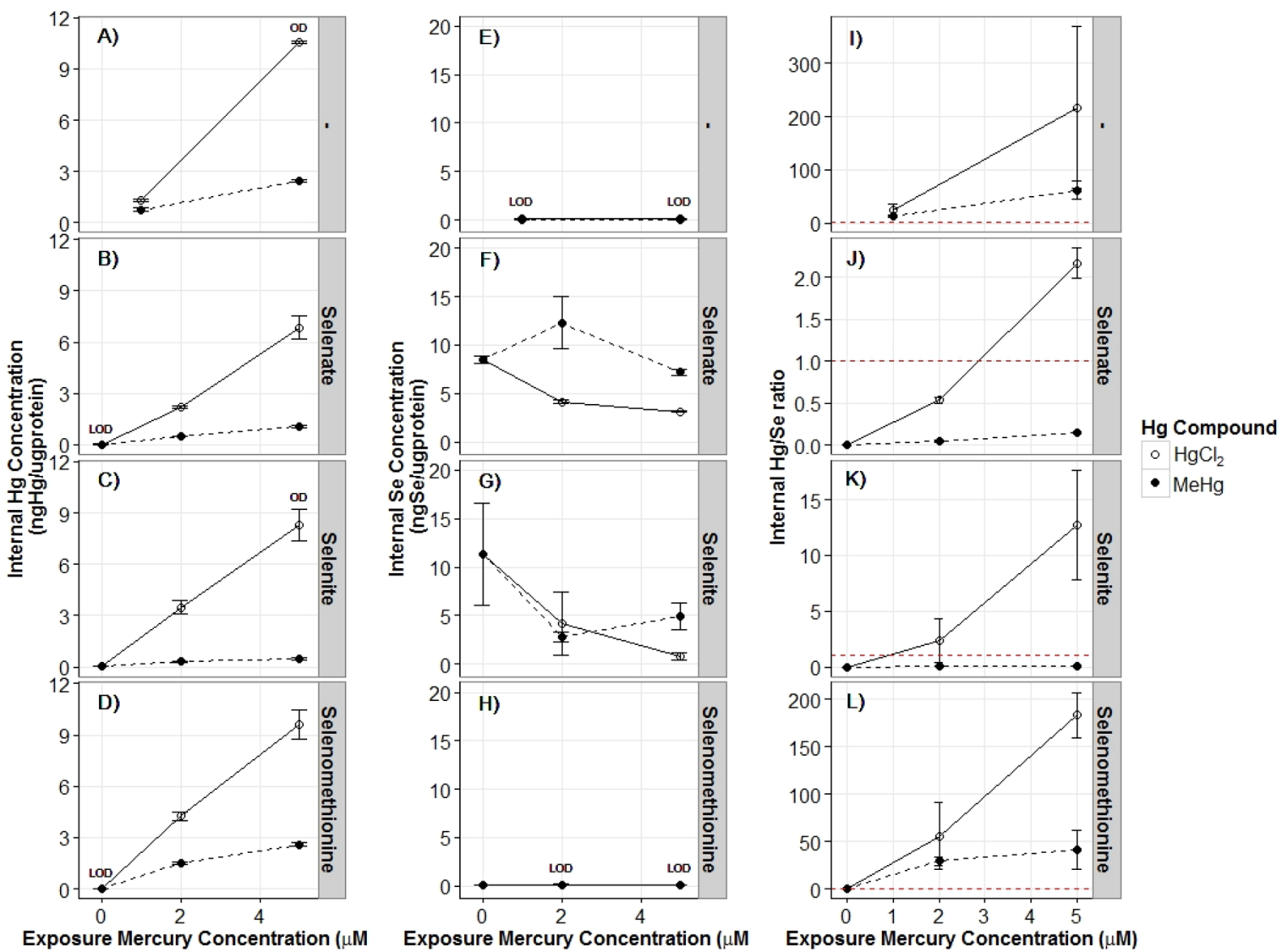

Figure 3. Interaction plots for internal mercury and selenium concentrations (average ng of compound/ $\mu \mathrm{g}$ of protein $\pm \mathrm{SE}$ ) and internal $\mathrm{Hg} / \mathrm{Se}$ ratios (average $\pm \mathrm{SE}$ ). The figure is grouped into three main sections with internal mercury concentrations are represented in the left panels $(\mathrm{A}-\mathrm{D})$, internal selenium concentrations are represented in the middle panels $(\mathrm{E}-\mathrm{H})$, and internal $\mathrm{Hg} / \mathrm{Se}$ ratios in the right panels (I-L). Each of these sections contains faceted plots to represent exposure to no selenium compounds (none; A, E, I), selenate ( $50 \mathrm{mM}$; B, F, J), selenite (1500 $\mu \mathrm{M}$; C, G, $\mathrm{K})$, or selenomethionine $(500 \mu \mathrm{M} ; \mathrm{D}, \mathrm{H}, \mathrm{L})$. The $x$-axis has categorically increasing mercury exposures $(\mu \mathrm{M})$ to either $\mathrm{HgCl} 2$ (open circle, solid line) or $\mathrm{MeHg}$ (closed circle, dotted line). In the internal $\mathrm{Hg} / \mathrm{Se}$ ratio section, note that the $y$-axis scale is different for each plot, and the red dashed line indicates a $1: 1 \mathrm{Hg} / \mathrm{Se}$ ratio. In the internal mercury and selenium sections, points with at least one value above or below detection limits are indicated by OD and LOD, respectively; for a full list of sample values, see Table SI-1. For the internal mercury plots, main effects for mercury compound and concentration and their interaction were significant $(p<0.05)$ for each selenium exposure. For the internal selenium plots, the main effect of mercury compound was significant $(p<0.05)$ in the selenate plot but not $(p=0.08)$ in the selenite or selenomethionine plots.

plicative models differed greatly (AIC and BIC score difference $>70$ ), with the multiplicative models having the lower AIC and BIC scores. The better model fit with the multiplicative models in these instances is likely due to the defined multiplicative interaction being a more intermediate response compared to the additive model.

Following $\mathrm{Se}$ (VI) exposures, antagonistic interactions were mainly observed at the highest $\mathrm{Se}(\mathrm{VI})$ dosing concentration $(50000 \mu \mathrm{M})$. Smaller $(<15 \%)$ antagonistic and greater than additive interactions also occurred at lower Se(VI) doses (Figure 2). Following $\mathrm{Se}(\mathrm{IV})$ exposures, antagonistic interactions only occurred at the highest $\mathrm{Se}$ (IV) dosing concentration $(1500 \mu \mathrm{M})$, with significant growth improvements (>20\%) observed in combination with both $\mathrm{MeHg}$ concentrations. Greater-than-additive interactions with $\mathrm{Se}(\mathrm{IV})$ were also observed at one coexposure with $\mathrm{HgCl}_{2}$ and multiple coexposures with $2 \mu \mathrm{M} \mathrm{MeHg}$ (Figure 2). Following SeMeth exposures, significant antagonistic interactions (>20\%) were observed at the highest Se dosing concentrations for all $\mathrm{Hg}$ compounds and doses. Smaller antagonistic interactions were also observed at lower SeMeth doses in combination with both low and high concentrations of $\mathrm{HgCl}_{2}$ and $\mathrm{MeHg}$ (Figure 2). Antagonistic relationships identified for some very high $(5 \mu \mathrm{M})$
$\mathrm{Hg}$ exposures (Figure 2, Table SI-3) should be taken with caution because growth was highly impaired at this $\mathrm{Hg}$ concentration. There were seven cases in which the expected nematode size was smaller than the size before dosing. These cases are indicated in Table SI-3.

Internal $\mathrm{Hg}$ and Se Exposure Determination. We next determined if the interactions observed at the highest Se dosing concentrations, which were uniformly antagonistic, were related to the intraorganismal $\mathrm{Se} / \mathrm{Hg}$ molar ratio. We measured internal $\mathrm{Hg}$ and $\mathrm{Se}$ concentrations for individual $\mathrm{Hg}$ exposures and for the coexposures that occurred at the highest Se dosing concentration for each Se compound. As expected, $\mathrm{Hg}$ concentrations increased with increasing exposure concentration, but unexpectedly, higher $\mathrm{Hg}$ concentrations were detected in $\mathrm{HgCl}_{2}$-exposed rather than $\mathrm{MeHg}$-exposed nematodes ( $p<0.05$ for $\mathrm{Hg}$ compound effect). In $\mathrm{Se}(\mathrm{IV})$ and $\mathrm{Se}(\mathrm{VI})$ coexposed nematodes, internal $\mathrm{HgCl}_{2}$ concentrations were reduced but not significantly $(p=0.074)$. In SeMeth and $\mathrm{MeHg}$ coexposed nematodes, the internal $\mathrm{Hg}$ concentration was similar to the internal concentration of the treatment exposed only to $\mathrm{MeHg}$, and the internal $\mathrm{Hg}$ concentration was significantly reduced in $\mathrm{Se}(\mathrm{IV})$ and $\mathrm{Se}(\mathrm{VI})$ coexposures $(p<0.05)$. Nematodes exposed to Se(IV) had 
significantly reduced internal $\mathrm{Hg}$ compared to the $\mathrm{Se}(\mathrm{VI})$ treatment (Figure 3).

Internal Se concentrations were not statistically significantly impacted by either $\mathrm{Hg}$ compound in SeMeth and $\mathrm{Se}(\mathrm{IV})$ coexposed nematodes (Figure 3). In nematodes exposed to $\mathrm{Se}(\mathrm{VI})$, the internal $\mathrm{Se}(\mathrm{VI})$ concentration was higher in $\mathrm{MeHg}$ coexposed nematodes (Figure 3).

Finally, we assessed the effects of coexposures on $\mathrm{Hg} / \mathrm{Se}$ molar ratios (Figure 3), and the relationship between those ratios and growth effects (Figure 4). We observed significant

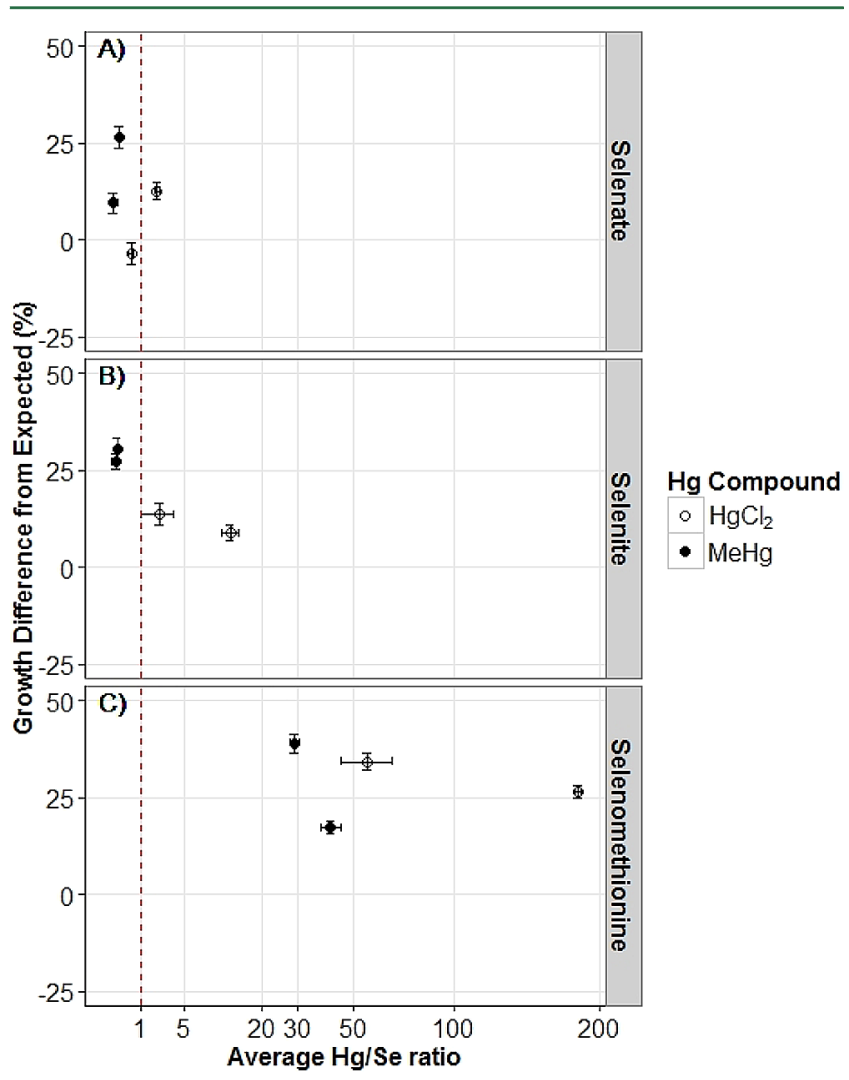

Figure 4. $\mathrm{Hg} / \mathrm{Se}$ ratio (average $\pm \mathrm{SE}$ ) plotted against nematode growth difference (average \% of control \pm SE) from expected growth under additive conditions for selenium-mercury coexposures at the highest selenium exposure. Faceted plots represent exposure to (A) selenate $(50 \mathrm{mM}),(\mathrm{B})$ selenite $(1500 \mu \mathrm{M})$, or $(\mathrm{C})$ selenomethionine $(500 \mu \mathrm{M}) . \mathrm{HgCl} 2$ and $\mathrm{MeHg}$ exposures are indicated by open and closed circles, respectively. Red dashed line indicates a 1:1 Hg/Se ratio.

main effects for $\mathrm{Hg}$ concentration and compound and their interaction on $\mathrm{Hg} / \mathrm{Se}$ molar ratios for $\mathrm{Se}(\mathrm{VI})$ and SeMeth (Figure 3). For $\mathrm{Se}(\mathrm{IV})$, the main effect of $\mathrm{Hg}$ compound was significant, but the main effect for $\mathrm{Hg}$ concentration ( $p=$ $0.053)$ and the interaction between compound and concentration $(p=0.055)$ were not. As Se concentrations were held constant at the highest exposure level, increasing the $\mathrm{Hg}$ exposures increased the $\mathrm{Hg} / \mathrm{Se}$ molar ratio, and the $\mathrm{Hg} / \mathrm{Se}$ molar ratio was higher in $\mathrm{HgCl}_{2}$ coexposed than in $\mathrm{MeHg}$ coexposed nematodes. Antagonistic interactions resulting in greater than expected growth were observed at $\mathrm{Hg} / \mathrm{Se}$ molar ratios both above and below 1 for all Se compounds at the highest Se exposure levels (Figure 4). We also observed one instance (Se(VI) treatment) in which a $\mathrm{Se} / \mathrm{Hg}$ molar ratio of $>1$ did not result in the reduction of growth inhibition (Figure 4).

\section{DISCUSSION}

We observed growth impairments from single exposures to either $\mathrm{Hg}$ or Se that were consistent with other C. elegans studies. Reduced growth was comparable for $\mathrm{MeHg}$ and $\mathrm{HgCl}_{2}$ and occurred in the low- $\mu \mathrm{M}$ range, as observed by McElwee and Freedman. ${ }^{20}$ At first glance, this finding is unexpected because $\mathrm{MeHg}$ is frequently identified as the more toxic compound for most end points, but in both of our studies, growth was reduced similarly on the basis of external dosing solution concentrations. However, our measurements of internal $\mathrm{Hg}$ demonstrated that $\mathrm{MeHg}$ was more toxic than $\mathrm{HgCl}_{2}$ because internal nematode $\mathrm{MeHg}$ concentrations were lower than $\mathrm{HgCl}_{2}$ concentrations for identical external exposure concentrations.

The tested Se compounds were at least 2 orders of magnitude less toxic than the $\mathrm{Hg}$ compounds. Biological impairments resulting from $\mathrm{Se}(\mathrm{IV})$ occurred in the same range $(1-5 \mathrm{mM})$ reported by $\mathrm{Li}$ et al. ${ }^{19}$ for growth impairment and by Morgan et al. ${ }^{34}$ for impaired motility. Growth sensitivity to Se varied greatly between compounds, with toxicity observed in following order: SeMeth $>\mathrm{Se}(\mathrm{IV})>\mathrm{Se}(\mathrm{VI})$; this order has also been observed in other invertebrates. ${ }^{29,38,39}$ Coexposure outcomes were not as straightforward.

In our experiments, the instances in which $\mathrm{Hg}$ and $\mathrm{Se}$ did interact were complex and depended greatly on the chemical compound and the concentration administered. For reference, most dosing Se concentrations that we utilized were in the range of total Se concentrations found in child $(2-32 \mu \mathrm{M})$ and adult $(3-12000 \mu \mathrm{M})$ blood and plasma in populations exposed to $\mathrm{Hg}$ through diet. ${ }^{42-47} \mathrm{We}$ observed growth impacts from coexposures that ranged from antagonistic to greater-thanadditive. Antagonism has been the most frequently reported $\mathrm{Hg}$ and Se interaction and was observed in this study primarily with $\mathrm{Se}(\mathrm{IV})$ and SeMeth exposures. Growth improvements, compared to the individual $\mathrm{Hg}$ exposure, were observed with $\mathrm{Se}(\mathrm{IV})$ and organic $\mathrm{Hg}$, while growth improvements were noted for SeMeth in combination with both inorganic and organic $\mathrm{Hg}$ (Figure 2). Some antagonistic interactions occurred at some lower Se exposures and resulted in small growth improvements $(\leq 13 \%)$, and biologically meaningful antagonism, which we defined here as that which altered growth by $20 \%$ or more, only occurred when the Se exposure was much greater than the $\mathrm{Hg}$ exposure (100-25000 times). Toxicity reduction at the highest $\mathrm{Se}$ exposures also varied between compounds, with SeMeth causing the greatest reduction in combination with both $\mathrm{Hg}$ compounds (34-47\%), followed by $\mathrm{Se}(\mathrm{IV})$ with $\mathrm{MeHg}(30-42 \%) \mathrm{Se}(\mathrm{IV})$ in combination with $\mathrm{HgCl}_{2}$ and $\mathrm{Se}(\mathrm{VI})$ with both $\mathrm{Hg}$ compounds provided 9-28\% toxicity reduction. Antagonism between $\mathrm{Hg}$ and $\mathrm{Se}$ has been observed previously, with other end-points with many different selenocompounds in a number of ameliorated or partially ameliorated end points including enzyme activity, enzyme expression, and DNA damage. ${ }^{8,18,48}$

In addition to the antagonistic interactions described above, we observed additive and greater than additive interactions. Additive impacts were most common, especially at the lower Se exposures (Figure 2). Various interactions between the two elements have also been noted in other studies. Impacts ranging from little impact of Se supplementation to reduction of toxicity were also highlighted in a rodent dietary study in which Se delayed and reduced MeHg's impact for some end points but not others. ${ }^{49}$ Though only observed to a small degree in 
this study, greater than additive toxicity has been noted in other aquatic toxicology studies, resulting in reduced survival and development in aquatic insect larvae, ${ }^{50}$ lower hatching success and survival in ducklings, ${ }^{51}$ and reduced reproduction in fish. ${ }^{10}$ This synergism in younger life-stages appears to have been noted most frequently in studies that have assessed end-points at young and adult life-stages. However, the same group that reported synergistic effects of reduced reproduction also observed partial mitigation of embryonic selenoprotein gene mRNA levels, GPX activity, and larval locomotion. ${ }^{18}$ The mechanisms that underlie greater than additive toxicity are not well-understood.

One theory that seeks to explain some of these interactions is that antagonism and toxicity mitigation occur when the $\mathrm{Se} / \mathrm{Hg}$ molar ratio is $\geq 1$. This hypothesis is based on the premise that when the two elements are present at equimolar ratios, Se binds to and sequesters Hg. ${ }^{14,17}$ However, the majority of the studies addressing $\mathrm{Se} / \mathrm{Hg}$ molar ratios have been ecological in nature, focusing on natural ratios present in fish. ${ }^{52-54}$ In laboratory studies with rodents, both beneficial and nonadvantageous health outcomes of Se coexposure have been noted. ${ }^{14,55}$ Furthermore, although Se has a beneficial impact on some health outcomes, there has not been strong evidence for interactions between $\mathrm{Hg}$ and $\mathrm{Se}$ in epidemiological studies. $^{42,43,46,47}$ The reasons for which different interactions have been observed are not entirely clear but could be attributable to study design differences including: different studies employing different species of $\mathrm{Hg}$ and Se, typically a relatively small number of concentrations, different species of test organism, and different toxic end-points. The results of our study, in which we directly tested outcomes in experiments in which Se/ $\mathrm{Hg}$ molar ratio were deliberately manipulated over a wide range of ratios do not support the $\mathrm{Se} / \mathrm{Hg}$ molar ratio hypothesis. Antagonism was not consistently observed when either the external or internal $\mathrm{Se} / \mathrm{Hg}$ molar ratio was $\geq 1$, suggesting that the simple model of Se-mediated sequestration of $\mathrm{Hg}$ is an insufficient explanation for antagonism. Another possibility, less dependent on the molar ratio per se, is that Se supplementation replenishes Se sequestered by $\mathrm{Hg}$, thereby rescuing toxicity by providing ample Se for selenoprotein production and activity. ${ }^{14,17}$ This hypothesis, however, presumes that all $\mathrm{Hg}$ toxicity can be explained by selenoprotein depletion or inhibition, which seems unlikely given that $\mathrm{Hg}$ also has a well-documented interaction with sulfhydryl groups in proteins. Of note, this possibility is especially unlikely in our model organism because $C$. elegans has only one selenoprotein. However, it is important to note that this study did not assess tissue-specific impacts or effects beyond growth. While this means that we capture many potentially important biological targets, it also means that we could not distinguish specific impacts at the cellular or tissue level. To address the potential interactions between the elements in the dosing solution, we calculated that changes in $\mathrm{Se}$ and $\mathrm{Hg}$ speciation and the binding of the two in solution are unlikely to explain the biological impacts observed.

The speciation of $\mathrm{Se}$ and $\mathrm{Hg}$ in exposure experiments was likely dependent on the $\mathrm{Se} / \mathrm{Hg}$ molar ratio and the type of Se and $\mathrm{Hg}$ tested. For example, the calculated equilibrium speciation for the exposure media in our study suggested that $\mathrm{Se}(\mathrm{VI})$ was not binding substantial amounts of $\mathrm{MeHg}^{+}$in the experimental solutions (Figure SI-2), even though we observed antagonism at the highest $\mathrm{Se}(\mathrm{IV}) / \mathrm{MeHg}$ molar ratio. $\mathrm{Se}(\mathrm{IV})$ also was not influencing inorganic $\mathrm{Hg}^{2+}$ and $\mathrm{MeHg}^{+}$speciation at most $\mathrm{Se} / \mathrm{Hg}$ molar ratios. The exception was the mixture with the highest $\mathrm{Se}(\mathrm{IV}) / \mathrm{MeHg}$ molar ratio (1500 $\mu \mathrm{M} \mathrm{Se}(\mathrm{IV})$ and $2 \mu \mathrm{M} \mathrm{MeHg}$ ), where the $\mathrm{CH}_{3} \mathrm{HgSeO}_{3}{ }^{-}$concentration was predicted to be $1.3 \mu \mathrm{M}$ (or $67 \%$ of the total $\mathrm{MeHg}$ ). We also note that at this highest $\mathrm{Se}(\mathrm{IV}) / \mathrm{MeHg}$ molar ratio, antagonistic effects were observed for the growth of the nematodes (Figure 2). Stability constants for $\mathrm{Hg}^{2+}$ complexes with $\mathrm{Se}(\mathrm{VI})$ and $\mathrm{Hg}^{2+}$ as well as $\mathrm{MeHg}^{+}$complexes with SeMeth were not found in the literature, so speciation calculations were not performed for these mixtures. Therefore, the effects of these ligands, particularly SeMeth, on $\mathrm{Hg}$ speciation in the exposure mixtures could not be determined. Overall, the changes in $\mathrm{Hg}$ speciation in the exposure medium coincided with antagonisms in one case ( $\mathrm{Se}(\mathrm{IV})-\mathrm{MeHg}$ mixtures) but not in other cases ( $\mathrm{Se}(\mathrm{VI})-\mathrm{MeHg}$ and $\mathrm{Se}(\mathrm{IV})-\mathrm{Hg}$ mixtures).

Understanding factors that may mitigate $\mathrm{Hg}$ toxicity is important to environmental and human health. Our experiments focused on Se and utilized multiple $\mathrm{Hg}$ and $\mathrm{Se}$ compounds and concentrations to assess interaction impacts on toxicity. Our results indicate that even in a simple system, the relationship between the $\mathrm{Hg}$ and $\mathrm{Se}$ is complex and that straight antagonism is not the only interaction. Our most noteworthy findings emphasize the importance of including $\mathrm{Se}$ compound as a part of the analysis when assessing $\mathrm{Hg}$ and $\mathrm{Se}$ interaction and de-emphasizing the weight given to the $\mathrm{Se} / \mathrm{Hg}$ molar ratio.

\section{ASSOCIATED CONTENT}

\section{Supporting Information}

The Supporting Information is available free of charge on the ACS Publications website at DOI: 10.1021/acs.est.5b06044.

Table SI-1: internal mercury and selenium concentrations (average ng of compound $/ \mu \mathrm{g}$ of protein) for nematodes exposed to selenium ( $50 \mathrm{mM}$ selenite, 1500 $\mu \mathrm{M}$ selenite, and $500 \mu \mathrm{M}$ selenomethionine) and mercury $\left(\mathrm{HgCl}_{2}, \mathrm{MeHg}\right)$. Table SI-2: stability constants for the mercury-selenium species considered in the equilibrium calculations. Table SI-3: expected growth ( $\operatorname{logEXT})$ following coexposure assuming an additive interaction between mercury and selenium compounds. Figure SI-1: nematode size (logEXT) dose-responses for individual mercury and selenium compounds. Figure SI-2: the calculated equilibrium speciation of $\mathrm{MeHg}$ species and selenite species for the $\mathrm{MeHg}$ +selenite test mixtures. Figure SI-3: equilibrium speciation of mercury in the $\mathrm{Hg}(\mathrm{II})$-selenite mixtures and the $\mathrm{MeHg}$-selenite mixtures. (PDF)

\section{AUTHOR INFORMATION}

\section{Corresponding Author}

*Phone: 919-613-8109; e-mail: joel.meyer@duke.edu.

\section{Notes}

The authors declare no competing financial interest.

\section{ACKNOWLEDGMENTS}

We thank Elena Turner for assistance with the COPAS Biosort. This research was supported in part by the U.S. Department of Energy (DE-SC0006938) and the National Institute of Environmental Health Sciences (R01ES024344). S.E.D. was supported by a doctoral scholarship from the Duke Global Health Institute. 


\section{REFERENCES}

(1) UNEP Global Mercury Assessment 2013: Sources, Emissions, Releases and Environmental Transport; UNEP Chemicals Branch: Geneva, Switzerland, 2013.

(2) Clarkson, T. W.; Magos, L. The toxicology of mercury and its chemical compounds. Crit. Rev. Toxicol. 2006, 36 (8), 609-662.

(3) Grandjean, P.; Weihe, P.; White, R. F.; Debes, F.; Araki, S.; Yokoyama, K.; Murata, K.; Sorensen, N.; Dahl, R.; Jorgensen, P. J. Cognitive deficit in 7-year-old children with prenatal exposure to methylmercury. Neurotoxicol. Teratol. 1997, 19 (6), 417-428.

(4) Lebel, J.; Mergler, D.; Lucotte, M.; Amorim, M.; Dolbec, J.; Miranda, D.; Arantes, G.; Rheault, I.; Pichet, P. Evidence of early nervous system dysfunction in Amazonian populations exposed to low-levels of methylmercury. Neurotoxicology 1996, 17 (1), 157-167.

(5) Drake, P. L.; Rojas, M.; Reh, C. M.; Mueller, C. A.; Jenkins, F. M. Occupational exposure to airborne mercury during gold mining operations near El Callao, Venezuela. Int. Arch. Occup. Environ. Health 2001, 74 (3), 206-212.

(6) Jarosinska, D.; Horvat, M.; Sallsten, G.; Mazzolai, B.; Dabkowska, B.; Prokopowicz, A.; Biesiada, M.; Barregard, L. Urinary mercury and biomarkers of early renal dysfunction in environmentally and occupationally exposed adults: A three-country study. Environ. Res. 2008, 108 (2), 224-232.

(7) Deng, D. F.; Teh, F. C.; Teh, S. J. Effect of dietary methylmercury and seleno-methionine on Sacramento splittail larvae. Sci. Total Environ. 2008, 407 (1), 197-203.

(8) El-Demerdash, F. M. Effects of selenium and mercury on the enzymatic activities and lipid peroxidation in brain, liver, and blood of rats. J. Environ. Sci. Health, Part B 2001, 36 (4), 489-499.

(9) Brandao, R.; Lara, F. S.; Pagliosa, L. B.; Soares, F. A.; Rocha, J. B. T.; Nogueira, C. W.; Farina, M. Hemolytic effects of sodium selenite and mercuric chloride in human blood. Drug Chem. Toxicol. 2005, 28 (4), 397-407.

(10) Penglase, S.; Hamre, K.; Ellingsen, S. Selenium and Mercury have a synergistic negative effect on fish reproduction. Aquat. Toxicol. 2014, 149, 16-24.

(11) Weber, D. N.; Connaughton, V. P.; Dellinger, J. A.; Klemer, D.; Udvadia, A.; Carvan, M. J. Selenomethionine reduces visual deficits due to developmental methylmercury exposures. Physiol. Behav. 2008, 93 (1-2), 250-260.

(12) Luque-Garcia, J. L.; Cabezas-Sanchez, P.; Anunciacao, D. S.; Camara, C. Analytical and bioanalytical approaches to unravel the selenium-mercury antagonism: A review. Anal. Chim. Acta 2013, 801, $1-13$.

(13) Cuvinaralar, M. L. A.; Furness, R. W. Mercury and Selenium Interaction - A Review. Ecotoxicol. Environ. Saf. 1991, 21 (3), 348-364.

(14) Ralston, N. V. C.; Blackwell, J. L.; Raymond, L. J. Importance of molar ratios in selenium-dependent protection against methylmercury toxicity. Biol. Trace Elem. Res. 2007, 119 (3), 255-268.

(15) Sormo, E. G.; Ciesielski, T. M.; Overjordet, I. B.; Lierhagen, S.; Eggen, G. S.; Berg, T.; Jenssen, B. M. Selenium Moderates Mercury Toxicity in Free-Ranging Freshwater Fish. Environ. Sci. Technol. 2011, 45 (15), 6561-6566.

(16) Sugiura, Y.; Tamai, Y.; Tanaka, H. Selenium Protection Against Mercury Toxicity - High Binding Affinity of Methylmercury by Selenium-Containing Ligands in Comparison with Sulfur-Containing Ligands. Bioinorg. Chem. 1978, 9 (2), 167-180.

(17) Ralston, N. V. C.; Azenkeng, A.; Raymond, L. J. MercuryDependent Inhibition of Selenoenzymes and Mercury Toxicity. In Methylmercury and Neurotoxicity, Current Topics in Neurotoxicity 2, Ceccatelli, S.; Aschner, M., Eds. 2012; pp 91-99.

(18) Penglase, S.; Hamre, K.; Ellingsen, S. Selenium prevents downregulation of antioxidant selenoprotein genes by methylmercury. Free Radical Biol. Med. 2014, 75, 95-104.

(19) Li, W.-H.; Ju, Y.-R.; Liao, C.-M.; Liao, V. H.-C. Assessment of selenium toxicity on the life cycle of Caenorhabditis elegans. Ecotoxicology 2014, 23 (7), 1245-1253.
(20) McElwee, M. K.; Freedman, J. H. Comparative toxicology of mercurials in Caenorhabditis elegans. Environ. Toxicol. Chem. 2011, 30 (9), 2135-2141.

(21) Turner, E. A.; Kroeger, G. L.; Arnold, M. C.; Thornton, B. L.; Di Giulio, R. T.; Meyer, J. N. Assessing Different Mechanisms of Toxicity in Mountaintop Removal/Valley Fill Coal Mining-Affected Watershed Samples Using Caenorhabditis elegans. PLoS One 2013, 8 (9), e75329.

(22) Honda, Y.; Honda, S. Life span extensions associated with upregulation of gene expression of antioxidant enzymes in Caenorhabditis elegans, studies of mutation in the age-1, PI3 kinase homologue and short-term exposure to hyperoxia. Journal of the American Aging Association 2002, 25 (1), 21-28.

(23) Jee, C.; Vanoaica, L.; Lee, J.; Park, B. J.; Ahnn, J. Thioredoxin is related to life span regulation and oxidative stress response in Caenorhabditis elegans. Genes to Cells 2005, 10 (12), 1203-1210.

(24) Johnson, W. M.; Yao, C.; Siedlak, S. L.; Wang, W. Z.; Zhu, X. W.; Caldwell, G. A.; Wilson-Delfosse, A. L.; Mieyal, J. J.; Chen, S. G. Glutaredoxin deficiency exacerbates neurodegeneration in C. elegans models of Parkinson's disease. Hum. Mol. Genet. 2015, 24 (5), 13221335.

(25) Sakamoto, T.; Maebayashi, K.; Nakagawa, Y.; Imai, H. Deletion of the four phospholipid hydroperoxide glutathione peroxidase genes accelerates aging in Caenorhabditis elegans. Genes to Cells 2014, 19 (10), 778-792.

(26) Buettner, C.; Harney, J. W.; Berry, M. J. The Caenorhabditis elegans homologue of thioredoxin reductase contains a selenocysteine insertion sequence (SECIS) element that differs from mammalian SECIS elements but directs selenocysteine incorporation. J. Biol. Chem. 1999, 274 (31), 21598-21602.

(27) Gladyshev, V. N.; Krause, M.; Xu, X. M.; Korotkov, K. V.; Kryukov, G. V.; Sun, Q. A.; Lee, B. J.; Wootton, J. C.; Hatfield, D. L. Selenocysteine-containing thioredoxin reductase in C-elegans. Biochem. Biophys. Res. Commun. 1999, 259 (2), 244-249.

(28) Kryukov, G. V.; Castellano, S.; Novoselov, S. V.; Lobanov, A. V.; Zehtab, O.; Guigo, R.; Gladyshev, V. N. Characterization of mammalian selenoproteomes. Science 2003, 300 (5624), 1439-1443.

(29) Boehler, C. J.; Raines, A. M.; Sunde, R. A. Deletion of Thioredoxin Reductase and Effects of Selenite and Selenate Toxicity in Caenorhabditis elegans. PLoS One 2013, 8 (8), 1-8.

(30) Li, W. H.; Hsu, F. L.; Liu, J. T.; Liao, V. H. C. The ameliorative and toxic effects of selenite on Caenorhabditis elegans. Food Chem. Toxicol. 2011, 49 (4), 812-819.

(31) Stefanello, S. T.; Gubert, P.; Puntel, B.; Mizdal, C. R.; de Campos, M. M.; Salman, S. M.; Dornelles, L.; Avila, D. S.; Aschner, M.; Soares, F. A. Protective effects of novel organic selenium compounds against oxidative stress in the nematode. Toxicology reports 2015, 2, 961-967.

(32) Li, W.-H.; Shi, Y.-C.; Chang, C.-H.; Huang, C.-W.; Liao, V. H.C. Selenite protects Caenorhabditis elegans from oxidative stress via DAF-16 and TRXR-1. Mol. Nutr. Food Res. 2014, 58 (4), 863-874.

(33) Li, W. H.; Shi, Y. C.; Tseng, I. L.; Liao, V. H. Protective efficacy of selenite against lead-induced neurotoxicity in Caenorhabditis elegans. PLoS One 2013, 8 (4), e62387.

(34) Morgan, K. L.; Estevez, A. O.; Mueller, C. L.; Cacho-Valadez, B.; Miranda-Vizuete, A.; Szewczyk, N. J.; Estevez, M. The Glutaredoxin GLRX-21 Functions to Prevent Selenium-Induced Oxidative Stress in Caenorhabditis elegans. Toxicol. Sci. 2010, 118 (2), 530-543.

(35) Lewis, J. A.; Fleming, J. T. Basic culture methods. Methods Cell Biol. 1995, 48 (48), 3-29.

(36) Meyer, J. N.; Lord, C. A.; Yang, X. Y. Y.; Turner, E. A.; Badireddy, A. R.; Marinakos, S. M.; Chilkoti, A.; Wiesner, M. R.; Auffan, M. Intracellular uptake and associated toxicity of silver nanoparticles in Caenorhabditis elegans. Aquat. Toxicol. 2010, 100 (2), $140-150$.

(37) Yang, X. Y.; Gondikas, A. P.; Marinakos, S. M.; Auffan, M.; Liu, J.; Hsu-Kim, H.; Meyer, J. N. Mechanism of Silver Nanoparticle Toxicity Is Dependent on Dissolved Silver and Surface Coating in Caenorhabditis elegans. Environ. Sci. Technol. 2012, 46 (2), 11191127. 
(38) Hyne, R. V.; Hogan, A. C.; Pablo, F.; Roach, A. C. Toxicity of selenomethionine- and seleno-contaminated sediment to the amphipod Corophium sp. Ecotoxicol. Environ. Saf. 2002, 52 (1), 30-37.

(39) Maier, K. J.; Foe, C. G.; Knight, A. W. Comparative Toxicity of Selenate, Selenite, Seleno-DL-Methionine and Seleno-DL-Cystine to Daphnia-Magna. Environ. Toxicol. Chem. 1993, 12 (4), 755-763.

(40) EPA. Method 7473: Mercury in Solids and Solutions by Thermal Decomposition, Amalgamation and Atomic Absorption Spectrophotometry. EPA: Washington, DC, 1998.

(41) Smith, R. D.; Martell, A. E. NIST Critical Stability Constants of Metal Complexes Database v. 2.0. NIST: Gaithersburg, MD, 1993.

(42) Ayotte, P.; Carrier, A.; Ouellet, N.; Boiteau, V.; Abdous, B.; Sidi, E. A. L.; Chateau-Degat, M. L.; Dewailly, E. Relation between Methylmercury Exposure and Plasma Paraoxonase Activity in Inuit Adults from Nunavik. Environ. Health Perspect. 2011, 119 (8), 10771083.

(43) Fillion, M.; Lemire, M.; Philibert, A.; Frenette, B.; Weiler, H. A.; Deguire, J. R.; Guimarães, J. R. D.; Larribe, F.; Barbosa, F.; Mergler, D. Visual acuity in fish consumers of the Brazilian Amazon: risks and benefits from local diet. Public Health Nutrition 2011, 14 (12), 22362244.

(44) Lemire, M.; Fillion, M.; Barbosa, F., Jr.; Guimarães, J. R. D.; Mergler, D. Elevated levels of selenium in the typical diet of Amazonian riverside populations. Sci. Total Environ. 2010, 408 (19), 4076-4084.

(45) Lemire, M.; Fillion, M.; Frenette, B.; Passos, C. J. S.; Guimarães, J. R. D.; Barbosa, F.; Mergler, D. Selenium from dietary sources and motor functions in the Brazilian Amazon. NeuroToxicology 2011, 32 (6), 944-953.

(46) Saint-Amour, D.; Roy, M. S.; Bastien, C.; Ayotte, P.; Dewailly, E.; Despres, C.; Gingras, S.; Muckle, G. Alterations of visual evoked potentials in preschool Inuit children exposed to methylmercury and polychlorinated biphenyls from a marine diet. NeuroToxicology 2006, 27 (4), 567-578.

(47) Steuerwald, U.; Weihe, P.; Jorgensen, P. J.; Bjerve, K.; Brock, J.; Heinzow, B.; Budtz-Jorgensen, E.; Grandjean, P. Maternal seafood diet, methylmercury exposure, and neonatal neurologic function. $J$. Pediatr. 2000, 136 (5), 599-605.

(48) Grotto, D.; Barcelos, G. R. M.; Valentini, J.; Antunes, L. M. G.; Angeli, J. P. F.; Garcia, S. C.; Barbosa, F. Low levels of methylmercury induce DNA damage in rats: protective effects of selenium. Arch. Toxicol. 2009, 83 (3), 249-254.

(49) Heath, J. C.; Banna, K. M.; Reed, M. N.; Pesek, E. F.; Cole, N.; Li, J.; Newland, M. C. Dietary selenium protects against selected signs of aging and methylmercury exposure. NeuroToxicology 2010, 31 (2), $169-179$.

(50) Jensen, P. D.; Sorensen, M. A.; Walton, W. E.; Trumble, J. T. Lethal and sublethal responses of an aquatic insect Culex quinquefasciatus (Diptera: Culicidae) challenged with individual and joint exposure to dissolved sodium selenate and methylmercury chloride. Environ. Toxicol. 2007, 22 (3), 287-294.

(51) Heinz, G. H.; Hoffman, D. J. Methylmercury chloride and selenomethionine interactions on health and reproduction in mallards. Environ. Toxicol. Chem. 1998, 17 (2), 139-145.

(52) Squadrone, S.; Benedetto, A.; Brizio, P.; Prearo, M.; Abete, M. C. Mercury and selenium in European catfish (Silurus glanis) from Northern Italian Rivers: Can molar ratio be a predictive factor for mercury toxicity in a top predator? Chemosphere 2015, 119, 24-30.

(53) Arribere, M. A.; Ribeiro Guevara, S. R.; Bubach, D. F.; Arcagni, M.; Vigliano, P. H. Selenium and mercury in native and introduced fish species of patagonian lakes, Argentina. Biol. Trace Elem. Res. 2008, 122 (1), 42-63.

(54) Peterson, S. A.; Ralston, N. V. C.; Peck, D. V.; Van Sickle, J.; Robertson, J. D.; Spate, V. L.; Morris, J. S. How Might Selenium Moderate the Toxic Effects of Mercury in Stream Fish of the Western US? Environ. Sci. Technol. 2009, 43 (10), 3919-3925.

(55) Ralston, N. V. C.; Ralston, C. R.; Blackwell, J. L.; Raymond, L. J. Dietary and tissue selenium in relation to methylmercury toxicity. NeuroToxicology 2008, 29 (5), 802-811. 